\title{
Direitos Humanos, Sustentabilidade Ambiental, Consumo e Cidadania
}

\author{
Daniel Rubens Cenci \\ Doutor em Meio Ambiente e Desenvolvimento, professor \\ do Departamento de Ciências Jurídicas e Sociais (DCJS) \\ da Universidade Regional do Noroeste do Rio Grande do \\ Sul - Unijuí; Professor do Programa de Pós-Graduação \\ Mestrado em Direitos Humanos, coordenador da Linha \\ de Pesquisa Direitos Humanos, Meio Ambiente e Novos \\ Direitos, coordenador do projeto de pesquisa CNPq " 0 \\ direito ambiental no contexto da sociedade de risco: \\ em busca da justiça ambiental e da sustentabilidade". \\ danielr@unijui.edu.br
}

\section{Tatiana Kessler Burmann}

Mestranda em Direitos Humanos pela Universidade Regional do Noroeste do Estado do Rio Grande do Sul - Unijuí; pesquisadora da Linha de Pesquisa Direitos Humanos, Meio Ambiente e Novos Direitos; pesquisadora CNPq, no projeto de pesquisa " 0 direito ambiental no contexto da sociedade de risco: em busca da justiça ambiental e da sustentabilidade". tati_burmann@hotmail.com

\section{Resumo}

A crise ambiental atual impõe questionamentos à racionalidade expressa no modelo de desenvolvimento orientado para a produção e consumo de bens. 0 consumo sustentável exige a adoção de práticas que transcendam as dimensões pessoais, articulem iniciativas coletivas por meio de grupos sociais, organizações da sociedade civil e políticas públicas. Temas como equidade, ética, educação ambiental, responsabilidade socioambiental, cidadania, fazem emergir um novo ator social promotor de mudanças em busca da sustentabilidade. Os desafios éticos exigem uma aliança global e intergeracional como condição fundamental para a garantia do direito ao meio ambiente ecologicamente equilibrado.

Palavras-chave: Consumo. Cidadania. Sustentabilidade. Crise ambiental. 


\title{
HUMAN RIGHTS, ENVIRONMENTAL SUSTAINABILITY, CONSUME AND CITIZENSHIP
}

\begin{abstract}
The actual environmental crisis imposes some questions to the reason expressed in the development model oriented for production and consume of material goods. The sustainable development involves the adoption of acts which transcend the individual dimensions, build collective initiatives through social groups, civil society organizations and public policies. Themes like equity etic, environmental education, social-environmental responsibility, citizenship, make emerge a new social actor, promoter of changes in search of sustainability. The etic challenges ask for a global and intergenerational alliance, like the fundamental condition to guarantee the right to an ecologically balanced environment.
\end{abstract}

Keywords: Consume. Citizenship. Sustainability. Environmental crisis.

\section{Sumário}

1 Introdução. 2 Crise socioambiental e a crise da modernidade. 3 Politização e despolitização do consumo: a emergência do sujeito consumidor. 4 Possibilidades e perspectivas para uma mudança rumo a sustentabilidade. 5 Referências. 


\section{INTRODUÇÃO}

A emergência da crise ambiental pode ser analisada sob diferentes aspectos. A opção feita no presente artigo pretende entrelaçar algumas ideias do campo ambiental e do campo social, especialmente no que versa o consumo, alcançando a dimensão da cidadania no sentido de entender as escolhas possíveis na construção de relações socioambientais sustentáveis, ou ainda, identificar possíveis caminhos para a superação do momento histórico atual, em busca da sustentabilidade.

Como ponto de partida desenvolve-se uma reflexão sobre a crise ambiental e a compreensão moderna da natureza, entendendo-se por moderna a construção da racionalidade instrumental e tecnológica, acalentada ao longo dos últimos séculos. As características mais marcantes emergem do Iluminismo e do Racionalismo, promovendo uma ruptura paradigmática profunda, pois se suplantam as teologias e mesmo filosofias, para dar lugar aos conhecimentos práticos e técnicos, saberes que promovem por um lado o crescimento econômico e fazem emergir um antropocentrismo exacerbado, levando à produção e consumo de produtos como novo signo de grandeza, de poder, de sucesso.

Um novo conjunto de valores que remetem à reflexão sobre a ética e a responsabilidade social, diante da crise ambiental, ou em linguagem mais atualizada, da crise socioambiental, se faz necessário. Percebe-se que o novo instrumento de regulação de todas as relações sociais e mesmo do homem com a natureza passa para a instrumentalidade, agora jurídica, num fazer permanente de novas regras que dão ao ser humano a centralidade e o senhorio perante o meio ambiente.

Neste campo adentra-se no debate da politização e da despolitização do tema do consumo, porquanto emerge como variável de valoração do cidadão, ou ainda, revela a denominada exclusão social. É a emergência do sujeito consumidor, que terá seu reconhecimento de cidadão respeitado 
quanto maior for sua capacidade de consumo. Neste sentido a corrida que se acelera a cada dia produziu não uma sociedade capaz de saciar suas necessidades, mas sim de consumo desenfreado e desnecessário de bens, em níveis comprometedores para a capacidade de resiliência dos sistemas planetários. Não só a vida humana está vinculada ao consumo para sobreviver, mas a ideia de cidadania tornou-se dependente do consumo.

Por derradeiro a reflexão adentra as experiências trazidas ao debate por diferentes caminhos, entre eles o movimento social de forma ampla, e rompendo os procedimentalismos da vida juridicizada e tecnificada, comete-se a audácia de sugerir possibilidades e perspectivas para uma mudança rumo à sustentabilidade.

Tais alternativas não se colocam como um menu a ser seguido para promover as mudanças ou metamorfoses necessárias à realização da vida, mas retomam campos da vida humana que nos parecem fundamentais e indispensáveis para a redefinição da cidadania capaz de alcançar referenciais para uma vida sustentável.

\section{CRISE SOCIOAMBIENTAL E A CRISE DA MODERNIDADE}

Os signos da modernidade expressam-se nas promessas de solução dos conflitos políticos, sociais, econômicos, tecnológicos, científicos, históricos e culturais que representaram os principais campos de lutas, cujas respostas para serem aceitas precisam ser fundadas nas ciências, pois a ciência emerge como a única fonte de conhecimento válido e, portanto, capaz de propiciar soluções verdadeiras. Tal modelo tecnocientífico que matiza a modernidade produz soluções físico-matemáticas para os problemas, ainda que estes sejam de caráter sociológico, antropológico, existencial ou ético. 
A modernidade significa a cisão, a antitradição, a derrubada das convenções, dos costumes e das crenças, a saída dos particularismos e a entrada do universalismo, ou, ainda, a saída do estado natural e a entrada na idade da razão e do Estado de Direito.

A racionalidade instrumental, típica da modernidade, que tem como fundamento a ética materialista do ter, apresenta sinais de exaustão à medida que as consequências desta mesma modernidade vislumbram um horizonte ambiental de crise, de insustentabilidade e colapso dos ecossistemas.

O tema central da modernidade, desde suas origens, envolve a luta pela emancipação do sujeito, e em nome da ciência, rejeita toda a herança judaico-cristã, o dualismo cristão e as teorias do direito natural que haviam provocado o nascimento das Declarações dos Direitos do Homem e do Cidadão. Passou-se das “trevas” para a "luz”, da superação da fé e da crença no sagrado para as certezas das ciências e esclarecimento da razão, da submissão aos dogmas religiosos para o dogma da razão. No propósito renascentista ressurgia imponente a razão como referência única do saber. Neste novo paradigma o conhecimento somente tem sentido se provado, se aprovado pela ciência com seus métodos, ritos e instâncias de validação. Com a modernidade, a única resposta para o homem está condicionada ao discurso científico.

O desafio posto é retirar o sagrado constructo da humanidade que por séculos justificou práticas políticas e religiosas e arrebanhou multidões, substituindo-o por um conhecimento que é pura razão.

As grandes promessas da modernidade, e a ânsia de responder às necessidades humanas, concentram-se nas conquistas da ciência e da tecnologia, impondo um processo crescente de valoração de todas as coisas, num sentido essencialmente materializado. Inicialmente, na linguagem marxista, atribuindo valor econômico às coisas pelo tempo de trabalho humano necessário à produção do bem; posteriormente, esvaziando-se 
deste sentido, à medida que se fundamentava na tecnologia e na ciência, em substituição ao trabalho humano, passando a valorar exclusivamente pela produtividade, pelo capital empregado.

Este novo referencial albergou não apenas os produtos da indústria, mas avançou em relação aos bens que não lhe pertenciam, especialmente a natureza, coisificando a terra e extraindo tudo aquilo que pudesse ter valor no grande mercado das relações econômicas e sociais, desde as coisas materiais até as culturas, os saberes históricos e invadiram até mesmo o direito à autodeterminação dos povos.

Passados mais de três séculos do advento da razão e o esboroamento das tradições, agora o esgotamento da modernidade transforma-se em sentimento de angústia e desencantamento do mundo. Vive-se a secularização e a separação entre o mundo dos fenômenos, da técnica, da ciência e o mundo do ser.

Esta ruptura se manifesta mais especificamente na diferenciação funcional dos subsistemas - separação entre a política e a religião, a economia e a política, a ciência e a arte, a vida privada e a vida pública - e acarreta o rompimento dos controles sociais e culturais que, antes, por meio da religião e do dogma, asseguravam a permanência de uma ordem. Não existe, porém, modernidade sem racionalização, mas também sem formação de um sujeito-no-mundo que se sente responsável perante si mesmo e a sociedade.

A racionalidade instrumental, de um lado, serve como um mecanismo para a organização da produção, a autoridade racional legal, a impessoalidade das leis e a organização do comércio e do Estado burocrático. Conforme lembra Touraine (2002), a subjetivação, presente nas concepções de homem, especialmente desde Nietzsche e Freud, consiste na transformação do indivíduo em sujeito, com o reaparecimento da ideia de construção do homem interior, psicológico, transcendente e subjetivo. 
Touraine, em seu livro Crítica da Modernidade (2002, p. 219), aponta, no entanto, paralelamente à hegemonia da razão, o surgimento de uma consciência do eu, que ele chama de subjetivização, ancorado nos estudos de Freud e nas transformações no pensamento, na Filosofia e nas visões de mundo que suas teorias causaram. Touraine afirma que "a modernidade triunfa com a ciência, mas também desde que as condutas humanas são reguladas pela consciência [...] e não mais pela busca da conformidade à ordem do mundo”. Trata-se do que hoje se denomina consciência crítica, sobre a qual discorrerá Habermas, entre outros.

Assim, com a quebra da tradição e, principalmente, do dogma, com a racionalização, a subjetivação e o entendimento de que "o homem é a medida de todas as coisas" (leia-se o homem como ser completo - corpo e mente - e com suas qualidades e defeitos), ele, o homem, toma posse gradativamente do seu espaço geográfico e histórico. Passa a se enxergar e a se assumir sujeito da própria história, libertado.

A ideia de modernidade, baseada apenas na racionalidade, definiu-se como o contrário de uma construção cultural, como a revelação de uma realidade objetiva. Trata-se de um campo no qual é possível identificar a diferença não por seu conteúdo apenas, ou pelo nível referencial da razão, mas principalmente por se tratar de uma época em que não se busca a afirmação e sim a renovação permanente, a adoção do novo como sinônimo de avanço.

Neste sentido, moderno significa antitradição, a derrubada das convenções, dos costumes e das crenças, a saída dos particularismos e a entrada no universalismo, ou ainda a saída do estado natural e a entrada na idade da razão. E nesta mesma ordem de ideias articula-se uma "racionalidade econômica e instrumental que molda as diferentes esferas do corpo social: os padrões tecnológicos, as práticas de produção, a organização burocrática e os aparelhos ideológicos do Estado” (Leff, 2006, p. 133). 
Não se trata de atribuir apenas aspectos sombrios ao conhecimento científico, mas um reposicionamento de saberes, necessário ao propósito trazido para o debate, em que os riscos produzidos pelo desenvolvimento científico e tecnológico da modernidade resultam da própria tentativa de negação da diversidade, bem como a pretensão da ciência enquanto única fonte de conhecimento verdadeiro.

A modernidade, entretanto, na tentativa de construção de uma consciência coletiva, impõe o esvaziamento de sentido do ser humano enquanto sujeito. A realização se dará a partir do coletivo e no coletivo os direitos de humanidade serão direitos coletivos. Na sociedade moderna, assim como Deus foi substituído pela ciência, os sábios, os filósofos, foram substituídos por juristas, economistas, administradores, engenheiros, etc.

A modernidade busca a maioridade, ou seja, o amadurecimento da razão. Ou seria o atrofiamento da razão? Como entender a desumanização do homem na sociedade que privilegia o conhecimento, a tecnologia e o consumo?

Para Leff (2001), o desenvolvimento científico moderno promoveu uma tecnologização da vida e uma economização da natureza, substituindo valores da natureza por valores subjetivos individuais e pessoais, transformando bens de uso em bens de negócio e de livre-mercado, dando curso a uma "crise de civilização, marcada pelo modelo de modernidade regido pelo predomínio de desenvolvimento da razão tecnológica sobre a organização da natureza”.

Atualmente apresenta-se a necessidade de construir um paradigma novo e inovador, no sentido não da negação do anteriormente construído, mas da necessidade de ressignificar o homem e a natureza, de reposicionar o valor da revolução científica e tecnológica construída na modernidade e de devolver o homem ao seu espaço e aos seus vínculos naturais. 


\section{POLITIZAÇÃO E DESPOLITIZAÇÃO DO CONSUMO: a Emergência do Sujeito Consumidor}

A vida humana está vinculada e dependente do consumo. A existência é necessariamente consumo. A vida biológica é permanentemente consumo. É impensável a existência humana sem o equivalente impacto. Consome-se permanentemente oxigênio, água, alimentos e a concomitante produção de impactos. Neste sentido compartilhamos com todos os outros organismos vivos o permanente fenômeno do consumo.

A esta altura do trabalho é importante diferenciar o conjunto de produtos de consumo, caracterizando a existência humana, como evento biopsicossocial. Como tal temos necessidades específicas como metabólicas, físicas e animais, destinadas à nutrição, proteção física, respiração, descanso, exercício físico, necessidades sexuais inerentes à própria reprodução da espécie, porém outros campos de necessidades pode-se identificar, como aquelas potencialmente realizáveis, que qualificam a vida humana, como a autonomia, a liberdade, a proteção, a autorrealização, desenvolvimento de atividades com sentido, afetos, amores, conhecimento e respeito moral, entre outras.

É inerente à natureza humana buscar transformar o meio que a cerca de modo a construir alicerces que garantam não só sua sobrevivência, mas o acesso a estruturas que lhe proporcionem qualidade de vida. Para concretizar essas metas o ser humano passa a fazer uso de ações que causam impactos tanto para o ambiente natural quanto para as relações sociais que estabelece a cada momento. Esses impactos ganham proporções maiores à medida que a população aumenta, apropria-se das tecnologias e se organiza dentro de políticas econômicas voltadas para a produção e acúmulo de bens, como solução para as mudanças nas exigências de demanda. 
É evidente que as mudanças causadas por esse desenvolvimento trazem questionamentos sobre o que de fato são essas exigências e se estariam sustentadas nas reais necessidades de cada um. Sempere (2009) defende que as necessidades humanas são carências anuladas no transcorrer da vida, como uma forma de proteção e de sobrevivência, para tentar atingir um estado pleno de bem-estar e de satisfação pessoal. Para Bauman (2008, p. 41), as necessidades sofreram alterações porque precisaram enquadrar-se em arranjos sociais resultantes da renovação de vontades e desejos. Dessa forma tornaram-se "força propulsora e operativa da sociedade" desempenhando papel significativo na execução de políticas de vida individuais.

Nessa perspectiva não há nas necessidades a característica de suprir o básico ou o que é mais importante, porque o mais importante também transformou-se, ganhou outros arranjos, baseado principalmente na produção para atender às demandas do mercado e à geração de lucros. A sociedade que surge na estrutura montada nesses novos atributos vale-se da alegação de tentar satisfazer os desejos humanos "em um grau que nenhuma outra do passado pôde alcançar, ou mesmo sonhar, mas a promessa de satisfação só permanece sedutora enquanto o desejo continua insatisfeito" (Bauman, 2008, p. 63).

O consumismo criado a partir desse descontrole da demanda contenta a política da necessidade do supérfluo que cria, por meio do crescimento econômico, a ilusão de que o progresso e a felicidade se instalam pelo mundo da riqueza material. O consumo passa a ser visto como um direito, ou um prazer e um dever para o cidadão. A felicidade reside em consumir cada dia mais e mais, e a cidadania igualmente passa a ser medida pela capacidade de consumo do indivíduo. Estaria assim construindo uma sociedade individualista e irresponsável com os proble- 
mas decorrentes dessas ações. A centralidade da condição exclusivamente material, tendo como ponto de equilíbrio e sustentabilidade não os sistemas de vida, mas o critério exclusivamente antropocêntrico.

Há nesse processo de desenvolvimento um equívoco que só é perceptível hoje pelo desgaste apresentado nos sinais da biosfera. Não há estofo na natureza capaz de suportar o avanço rápido das transformações tecnológicas, geográficas e biológicas causadas pela busca obstinada do homem em satisfazer seus desejos.

Há índices crescentes de produção de resíduos que impactam definitivamente o potencial ecológico. O acúmulo de lixo é um sério problema a ser enfrentado e solucionado pelas gerações deste século. Energia e resíduos figuram entre os temas mais desafiadores. $\mathrm{O}$ modo de produção e de consumo atuais são adversidades resultantes da razão humana e que precisam ser repensadas para que o meio ambiente possa suportar os níveis de consumo e recuperar-se de alguma forma dos impactos da devastação sem precedentes imposta pela sociedade consumista.

A aquisição de bens hoje é a chave principal nas relações econômicas. Dela nasceram as sociedades de consumo que recebem constantemente atenção do mercado econômico. Estes visam de algum modo a viciar o consumidor na busca incessante de satisfazer seus desejos, mesmo depois de torná-los realidade, a continuar procurando, porque a aquisição desse bem ou serviço não trouxe a tranquilidade e sensação de saciedade plena. Bauman alerta para a compulsão criada por esse vício que "ocorre desde que o impulso para buscar soluções de problemas e alívio para dores e ansiedades nas lojas, e apenas nelas, continue sendo um aspecto do comportamento não apenas destinado, mas encorajado com avidez, a se condensar num hábito ou estratégia sem alternativa aparente” (2008, p. 64). 
O hábito de fazer compras hoje recebe o nome de consumismo, porque há insatisfação na concretização desses desejos, motivados por uma política que ilude o consumidor com uma satisfação suficiente e crescente de suas necessidades e aspirações materiais, almejando que não lute contra a pressão a que está submetido, criando-lhe por vezes necessidades supérfluas (Sempere, 2009).

Essa pressão é reforçada pelo mercado de consumo que desvaloriza as antigas ofertas no exato momento em que novas se criam, a fim de esvaziar a área da demanda pública para que outros e novos produtos tomem seu espaço (Bauman, 2008), num círculo vicioso e maléfico que é expandido às pessoas como verdades de valor para que a economia permaneça aquecida, diminuindo um risco de crise econômica, ainda que para isso se aumente a pressão sobre o planeta e se ameace a biosfera.

Nesse contexto emerge uma sociedade mercantil na qual a grande maioria dos bens e serviços se apresentam como mercadorias, e nessa voracidade do ter e na pura realização centrada no ter, os riscos e as consequências nem sempre são observadas ou levadas a sério. A sociedade vigente é, sem dúvida, profundamente antiecológica, constituindo-se em um dos fatores explicativos da atual degradação do sistema-Terra (Boff, 2004).

Alguns teóricos argumentam que seria preciso uma renovação das necessidades humanas para que a natureza pudesse ser preservada, no entanto Bauman adverte que

não é a criação de novas necessidades [...] que constitui a principal preocupação da sociedade de consumidores. É o desdém e o desprezo pelas necessidades de ontem e a ridicularização e deturpação de seus objetos, agora passés, e mais ainda a difamação da própria idéia de que a vida de consumo deveria ser guiada pela satisfação das necessidades que mantêm vivos o consumismo e a economia do consumo. A maquiagem bege, que na última estação era sinal de ousadia, agora não é apenas uma cor que está ficando fora da moda, mas uma cor feia e 
monótona e também o estigma vergonhoso de um rótulo de ignorância, indolência e incapacidade e inferioridade total, com o ato que não faz muito tempo, significava rebeldia, audácia e "estar à frente da tendência de estilo" rapidamente se transformando em sintoma de preguiça e covardia, sinal de ter ficado atrás da tendência, talvez até mesmo de que se está ficando necessitado (2008, p. 127-128).

Há uma crise não só ecológica, mas um conflito de civilização que possui como características o domínio extremo da natureza, a industrialização, a tecnificação, a racionalização e a concentração humana. A crise ambiental e de civilização significa que estão sendo questionados os pilares da sociedade resultante do processo mercantil, cuja desenvoltura tem demonstrado até agora forte desequilíbrio, tanto nas diferenciações sociais, divisão do trabalho e urbanização quanto na concentração de poder político e econômico (Ruscheinsky, 2002).

É urgente a renovação da sociedade de consumo por outra que introduza critérios de vida coletiva, em substituição à corrente individualista dominante. A natureza carece de ações humanas que não a esgotem, que a valorizem e respeitem suas formas de regeneração. Repensar o comportamento a partir da ética afeta o comportamento individual de homens e mulheres que pretendem construir a história como atores sociais e sujeitos da sociedade ou dos grupos à qual pertencem. Ruscheinsky amplia a noção de ética para o consumo quando avalia que essa nova postura "implica uma construção intersubjetiva da consciência moral, na qual as decisões primam por uma coerência racional e pela consideração do outro como um igual, ou melhor, como um par para o diálogo na pluralidade, apesar das diferenças” (2002, p. 68).

A transformação do papel do homem e da mulher tanto na produção de bens quanto no consumo requer uma análise sobre seus limites e possibilidades, para além das imagens publicitárias e do apelo dos interesses 
de mercado. "Caberia, contudo, a análise dos limites e das possibilidades de que os consumidores possam constituir novos projetos, novas utopias e novas formas de luta política [...]” (Portilho, 2005, p.168).

A luta política deve ser assumida por esse novo sujeito, que se entende como consumidor responsável, adquirindo o direito cívico de intervir nas dimensões essenciais do metabolismo socionatural (Sempere, 2009). O significado de ser cidadão consumidor é o de recuperar o poder de decisão sobre um bem público, exercendo a cidadania responsável e buscando critérios adequados que possibilitem a equidade social e a sustentabilidade ecológica.

É importante que esse novo ator social esteja engajado a ações coletivas, contribuindo na tarefa de reconstrução da esfera política para que pense projetos de sustentabilidade. Portilho apresenta a partir dessa ideia a hipótese da politização das práticas de consumo, que representaria a "possibilidade de luta e participação política, reconfigurando as relações entre as esferas pública e privada" (2005, p. 207). O consumo pode ser importante alternativa de constituição de sujeitos sociais ativos e de cidadão, desde que cada consumidor desempenhe sua função dentro da lógica consciente e de responsabilidade.

A partir destas análises, poderíamos argumentar que a importância do papel do consumidor tem evoluído em consequiência de alguns fatores que têm transformado a sociedade nas últimas quatro ou cinco décadas, como a globalização, a destradicionalização e a reflexividade social. Estes acontecimentos são particularmente importantes nos países industrializados, mas seu impacto é cada vez mais mundial (Portilho, 2005, p. 210).

Nesse contexto, os movimentos sociais são fundamentais, porque aquecem o debate, estimulam e cobram os aspectos sociais e ambientais e criam redes de intercâmbio de informação e aprendizagem do exercício da cidadania. O ser humano pensando no meio ambiente e em causas 
coletivas mantém o equilíbrio da vida natural quando impõe limites aos seus próprios desejos. Na explicação de Boff, “ele não é apenas um ser de desejos. Somente o desejo o tornaria antropocêntrico e mimético. Ele é também e fundamentalmente um ser de solidariedade e de comunhão. Quando reforça estas dimensões, entra em sintonia com a dinâmica universal. [...] Então realiza sua dimensão ética” (2004, p. 188).

Com efeito, o consumidor responsável precisa renunciar a algum conforto, a algum exagero para poder contribuir efetivamente na melhoria do planeta. Sempere (2009) chega a defender o uso de menos tecnologia, menos produtos industrializados, uma sociedade menor, porém isso poderia causar um caos. Por isso as dificuldades no consumo consciente são enormes, e dependerão fortemente das ações políticas da administração pública, como também da fiscalização por parte da população para que alcancem um resultado satisfatório na solução da crise ambiental e nos problemas sociais.

As ações em favor de um novo consumidor se espalham pelo planeta, ainda tímidas e desconectadas de outras ações e políticas efetivas, pois são iniciativas quase que unilaterais, propostas por cidadãos. Neste sentido, grupos de "consumo alternativo”, “consumo limpo”, "consumo responsável”, “consumo verde”, “consumo consciente”, “consumo sustentável" entre outros, dão conta de iniciativas claras com o objetivo de revisar o comportamento do homem consumista, para propor formas de vida com menos tecnologia, menos produtos, menos energia, menos fórmulas químicas, menos consumo, que no mesmo horizonte focalizam a melhor qualidade de vida e a sustentabilidade planetária.

O fortalecimento de movimentos fundados em princípios ecológicos mais recentemente articulados em redes, igualmente com diferentes denominações, entre as quais as "redes de economia solidária", "redes de comércio justo”, ampliam os laços de responsabilidade social e ambiental, com foco na sustentabilidade. 
Ainda há, todavia, um paradoxo destes comportamentos em relação à definição dos grandes planos de investimentos voltados ao desenvolvimento. Trata-se de projetos que têm por objetivo produzir mais e oferecer mais produtos para consumo. Ainda que numa primeira dimensão se necessite de produtos para viver, é indisfarçável o caráter prioritariamente econômico dos empreendimentos.

Surgem de maneira esparsa iniciativas que incorporam a preocupação em produzir de forma mais ecológica, porém não conseguindo mudar o paradigma de consumo, fundante do atual modelo de desenvolvimento e que induz ao consumismo, de forma cada vez mais acelerada, impondo impactos igualmente de insustentabilidade aos sistemas naturais.

Oportuno retomar o conceito de resiliência ecológica, segundo o qual sustentabilidade exige respeito à capacidade de um ecossistema de recuperar seu estado inicial depois que ações humanas o alteraram.

Todas as estatísticas mundiais sobre condições dos bens naturais, como água, solo, florestas, e todo um conjunto de produtos extraídos do ambiente, e fundamentais à vida humana e do planeta, encontram-se em abalo de estoques pelo uso desenfreado, causando impacto direto na qualidade de vida, pela redução de quantidades, num crescimento inversamente proporcional ao aumento populacional. Resume-se numa impossibilidade de seguir fazendo "mais do mesmo". Agrava-se vertiginosamente a crise, se buscarmos levantamentos decorrentes das formas perversas de uso dos bens naturais, como o caso da energia e das invenções humanas, a exemplo da construção de usinas de energia atômica nas regiões do mundo mais vulneráveis a eventos naturais, como terremotos, sobre os quais o homem não tem nenhuma forma de evitar a ocorrência.

Neste contexto, ainda assim, o ser humano segue com um modelo de desenvolvimento econômico de produção de bens, cuja dinâmica centra-se no consumo. Em sentido genérico os resultados deste modelo, 
traduzem-se substâncias que abrangem desde resíduos da energia atômica, produzidos pelo macronegócio, até os resíduos sanitários produzidos pelos cidadãos.

Há, portanto, uma forma de vida de alto impacto, pois é de alta produção de resíduos. Nas palavras de Bauman (2008), vidas para consumo, numa fórmula que se acelera a cada dia. Segundo este autor, este processo converte o próprio ser humano em mercadoria.

Se em sentido clássico o duelo tradicional do modelo de desenvolvimento capitalista se traduzia pela contradição capital - trabalho, o nível de esgotamento imposto pela face atual do modelo indubitavelmente se expressa na contradição capital - ambiente. Uma aceleração infinita de produção de bens em escala, sobre uma base de insumos e produtos primários, frágil e finita.

Parece irreversível o atual processo, e ficam em aberto dúvidas e perguntas sobre os rumos para os quais caminha a humanidade. Seria a humanidade capaz de reposicionar o conjunto de necessidades instrumentalizadas pelo mercado, valorizando as necessidades biopsicossociais? Este tema desafiador nos incita a buscar alternativas. Se respostas objetivas no curto prazo não se vislumbram, sinais de mudança surgem em diferentes cantos do planeta, alguns como ação consciente, outros como ação política e outros, ainda, como necessidade de alternativas aos quadros de crise ecológica emergente. Sobre estes e outros aspectos trataremos na sequência deste trabalho.

\section{POSSIBILIDADES E PERSPECTIVAS PARA UMA MUDANÇA RUMO À SUSTENTABILIDADE}

Sem presunção de apresentar um manual de soluções, como fórmula infalível de superação da sociedade consumista e insustentável até aqui caracterizada, buscaremos sinais e caminhos possíveis que podem 
contribuir para formas de vida mais sustentáveis, que possam efetivamente reposicionar o homem em relação à natureza, deixando de ser mero explorador, mas seu conviva. Para tanto inúmeras iniciativas precisam ser lembradas e colocadas como prioridade na agenda do dia. Os recursos tecnológicos são aliados na resolução dos problemas ambientais, mas é preciso ética e responsabilidade nesse uso. Ruscheinsky exemplifica observando que "[...] em face de tudo aquilo que eventualmente podemos fazer com ajuda da ciência e da tecnologia, que nem tudo o que podemos devemos querer fazer; ou, mais resumidamente, que não devemos querer tudo o que podemos fazer" (2002, p. 45).

As ações na ótica da cidadania como responsabilidade no consumo devem estar alicerçadas no caráter coletivo para que alcance uma dimensão transformadora. As mudanças buscadas devem acontecer no plano de uma coletividade, todos envolvidos pelas relações sociais em um espaço geográfico. Só há sentido no desenvolvimento sustentável quando este proporciona melhoria na qualidade de vida, o que inclui não só as relações sociais e a preservação do meio ambiente, mas as oportunidades criadas para o exercício da cidadania.

As transformações no tipo de consumo exigem mudanças de hábitos e de atitudes e alguém deve em algum momento passar a viver de modo diferente. Assim, as ações coletivas e políticas necessárias para essa renovação podem ser organizadas dentro de técnicas produtivas que estabeleçam um modelo do uso energético do planeta e uma melhor distribuição territorial das atividades humanas (Sempere, 2009), diminuindo o emprego frequente de transportes e máquinas de alto impacto para a produção de bens.

Adotar uma política que dê prioridade ao investimento em técnicas ecologicamente sustentáveis, combatendo as desigualdades, daria suporte para que mais consumidores tornem-se responsáveis por suas escolhas, diminuindo o esgotamento dos recursos naturais como também o dis- 
tanciamento entre classes. Não esqueçamos que a crise ambiental está intimamente ligada à crise humana, os efeitos do revés do consumo são sentidos em ambas as partes, dependendo drasticamente de um repensar das necessidades para que as posturas adotadas possam levar a sociedade para o caminho da sustentabilidade de fato.

A análise das promessas e as armadilhas do "consumo verde" e do próprio “consumo sustentável” são fundamentais, porquanto este pode se confundir com aquele no momento em que busca apenas mudar os padrões de consumo, não se preocupando com a diminuição dos seus níveis, bem como com as questões relacionadas à desigualdade social e ao acesso aos recursos naturais. Cabe resgatar, no entanto, o potencial emancipatório contido na ideia de consumo sustentável, concebido como um projeto alternativo que deve englobar grupos e organizações na busca de uma maior politização do consumo por meio de outra racionalidade que não a econômica, levando em conta questões éticas que contribuam para alcançar a desejada sociedade sustentável.

Dessa maneira, o consumo sustentável implica necessariamente numa “ambientalização do consumo”, no sentido de caracterizar práticas capazes de transpor as dimensões individuais na medida em que articulam preocupações privadas e públicas. Sendo assim, o consumo sustentável representa um salto qualitativo de complexa realização, agregando um conjunto de características que ligam temas como equidade, ética, defesa do meio ambiente e cidadania, enfatizando a importância de práticas coletivas como norteadoras de um processo que, embora englobe os consumidores individuais, demanda compromissos e atitudes de dimensão coletiva, portanto tomadas no âmbito dos movimentos sociais e de ordem política. O documento oficial da Agenda 21 define como exigência a abordagem internacional do tema, para que se possa obter padrões de consumo sustentável. Tal documento referendado em 2012, na Rio +20 , retoma os grandes temas ambientais e fortalece a emblemática crise de acesso à 
alimentação, atribuindo novo conteúdo ao desenvolvimento sustentável, não como algo novo, mas fortalecendo a temática do acesso à alimentação e a superação da exclusão social, na proteção aos direitos humanos.

A concepção da crise ambiental tomada do ponto de vista do consumo, destacando as possibilidades do consumidor como novo ator social e a relação entre a esfera privada do consumidor e a esfera pública do cidadão, não pode ser apenas opção, mas necessidade, porquanto é a possibilidade de restabelecer a resiliência aos diferentes ecossistemas planetários e a manutenção da biodiversidade.

$\mathrm{Na}$ dimensão internacional a Organização das Nações Unidas (ONU) definiu entre os temas primordiais para um mundo sustentável um conjunto de 40 grandes temas, estruturados em 40 capítulos da Agenda 21, sendo o capítulo de número 4, destinado ao tema da Mudança dos Padrões de Consumo, subdividido em dois focos:

a) exame dos padrões insustentáveis de produção e consumo e

b) desenvolvimento de políticas e estratégias nacionais de estímulo a mudanças nos padrões insustentáveis de consumo.

Observa-se que pela própria adjetivação agregada ao tema do consumo, a insustentabilidade, está no centro da preocupação mundial no que tange à agenda ambiental planetária. Referido documento é enfático, destacando que nenhum processo de desenvolvimento e prosperidade de um país poderá acontecer à custa de prejuízos sociais e ambientais dos demais. Desenvolver de forma sustentável exige estar articulado e comprometido com os demais países. Impõe-se, pois, uma dimensão ética de solidariedade universal, como princípio fundamental para o desenvolvimento sustentável. 
Outro testemunho da preocupação direta e indireta com o tema do consumo, o documento da Agenda 21, focaliza em vários pontos a questão da mudança nos padrões de consumo. Entre os temas figuram energia, transportes, resíduos, transferências de tecnologias, crescimento demográfico, sustentabilidade, entre outros.

Trata-se de um tema abordado de forma objetiva, mas também de tangência transversal, porquanto a pobreza está intimamente ligada ao consumo. Enquanto a pobreza enfrenta determinados tipos de pressão ambiental, agravando a pobreza, as principais causas da deterioração ininterrupta do meio ambiente mundial são os padrões insustentáveis de consumo e produção, especialmente nos países industrializados.

O mencionado documento oferece ainda um conjunto de objetivos básicos nas ações para tratar da questão do consumo e do estilo de vida:

a) todos os países devem empenhar-se na promoção de padrões sustentáveis de consumo;

b) os países desenvolvidos devem assumir a liderança na obtenção de padrões sustentáveis de consumo;

c) os países em desenvolvimento devem procurar atingir padrões sustentáveis de consumo, garantindo o atendimento das necessidades básicas dos pobres e, ao mesmo tempo, evitando padrões insustentáveis, especialmente os países industrializados, geralmente considerados particularmente nocivos ao meio ambiente, ineficazes e dispendiosos. Isso exige um reforço do apoio tecnológico e de outras formas de assistência por parte dos países industrializados.

Observa-se nos termos da agenda mundial a presença de elementos fundamentais para avançar no debate sobre sustentabilidade. Não é possível ignorar a injustiça social para tratar dos temas ambientais e da sustentabilidade. Onde a necessidade ainda é alcançar padrões mínimos de consumo, seria antiético propor a redução do consumo, enquanto do ponto 
de vista dos países mais desenvolvidos é antiético pretender propor aos demais consumo sustentável sem incluir o esforço próprio para mudanças paradigmáticas, especialmente reduzindo níveis de consumo.

Neste sentido cabe retornar às considerações e reflexões propostas no início deste artigo, porquanto se trata de propor novos conceitos para o desenvolvimento e prosperidade, e aqui nos apoiamos no debate recente, levantado por alguns poucos países, raros movimentos sociais, cujo conteúdo desconcerta os conceitos tradicionais de desenvolvimento e suas concepções centradas na economia. O índice FIB - Felicidade Interna Bruta, num contraponto ao PIB - Produto Interno Bruto uma abordagem holística da sociedade, questiona as necessidades humanas da sociedade de consumo, e propõe outro olhar para a qualidade de vida e a sustentabilidade, propondo-se a responder às necessidades tanto materiais quanto espirituais das pessoas, sem o que não seria possível tornar realidade uma sociedade sustentável.

Avançou-se significativamente na compreensão de que o saber maduro é necessariamente interdisciplinar, transdisciplinar, todavia, na prática, segue-se os protocolos tradicionais de que desenvolvimento equivale a avanço do Produto Interno Bruto (PIB), da renda per capita, das toneladas de produtos extraídos a cada safra, e assim por diante, sempre focando dados da economia, abandonando o tema social e a destruição ecológica promovida pelo chamado modelo economicista e desenvolvimentista.

Neste sentido o FIB é audacioso e inovador, motivo pelo qual se inicia esta reflexão sobre a proposta. Seu núcleo é o postulado de que o bem-estar físico e vital - social e econômico -, mental e espiritual devem ser desenvolvidos simultaneamente no mundo contemporâneo. O objetivo do índice FIB é criar a conceituação e a motivação para um caminho alternativo para alcançar o desenvolvimento sustentável, que nutra o processo de construção de um ser humano e sociedade desenvolvidos em 
sua plenitude. Este caminho alternativo toma o FIB como referência para o planejamento e a realização do desenvolvimento econômico e tecnológico, portanto orientando-o para seu fim maior que é o desenvolvimento humano e social.

O desafio do FIB é operacional, mas antes de tudo conceitual, paradigmático, civilizacional, e está em surpreendente sincronia com a crise de paradigma civilizatório que a humanidade vive neste início de século.

A proposta leva em consideração um conjunto de indicadores que cobrem nove campos da vida familiar e social da população, sem excluir a economia, porém reservando a este tema apenas uma das nove dimensões ponderadas como fundamentais para a realização humana. Assim destacam-se os seguintes temas:

1. Padrão de vida - tem a ver com o acesso aos bens que respondem às necessidades materiais e fazem a economia real girar; 2 . Boa governança - partilha do poder de decisões e de gestão da economia e do desenvolvimento. A relação Estado, economia social, economia privada buscando equação de equilíbrio; 3 . Acesso à educação; 4. Acesso à saúde; 5. Resiliência ecológica - capacidade de um ecossistema de recuperar seu estado inicial depois que ações humanas o alteraram, como fundamento e limite dos níveis de impacto que se possa causar no processo de produção; 6. Diversidade cultural; 7. Vitalidade comunitária; 8. Utilização equilibrada do tempo; 9. Bem-estar psicológico e espiritual.

Um dos princípios que guiam a aplicação dos nove campos às políticas públicas é que qualquer sobrevalorização de um dos fatores gerará desequilíbrio e prejuízo para os outros. Ou seja, o desenvolvimento socioeconômico tem de ser harmônico na relação com os demais fatores. 
Outro princípio é que a realização equânime de cada um dos nove campos não ocorre espontaneamente. É necessário um planejamento do desenvolvimento econômico e tecnológico, orientando a atividade econômica para a realização das condições que geram bem-estar humano e felicidade.

Segundo essa metodologia proposta para identificar um sentido pleno para o desenvolvimento, há que se reconhecer que a economia centrada no lucro e na acumulação individual de riqueza material por meio da mais cruel competição e do corporativismo egocêntrico não propicia as condições para o desenvolvimento integral das pessoas e coletividades humanas, como tem dado provas o estado atual das sociedades que a adotam mundo afora.

Neste sentido a proposta se coaduna com o preconizado pela Agenda 21 sobre o tema, especialmente no que respeita à resiliência, dado que propõe o documento da ONU: "identificar, em nível global, padrões equilibrados de consumo que a terra tenha condições de suportar em longo prazo" (Brasil, 2001).

Na sequência propõe o documento o desenvolvimento de novos conceitos de crescimento econômico sustentável e prosperidade e dentro das possibilidades de tornar efetivas tais concepções teóricas, sugere mudanças nos padrões insustentáveis de consumo e a produção dos valores que estimulam modelos de consumo e estilos de vida sustentáveis. Requer os esforços conjuntos de governos, consumidores e produtores, e atenção especial ao papel desempenhado por mulheres e famílias enquanto consumidores, bem como aos impactos potenciais de seu poder aquisitivo, combinado sobre economia.

Percebe-se que a proposição dos documentos oficiais comunga da compreensão ampliada para o conceito de sustentabilidade para que as mudanças se efetivem, todavia as concepções teóricas têm se mostrado inertes diante do avassalador poder de sedução imposto pelo consumismo. 
E neste sentido há um esmaecimento do conhecimento teórico e das novas racionalidades mais sustentáveis, em favor da racionalidade econômica e seus tentáculos.

Não há sustentabilidade na especialização de conhecimentos propostos pela modernidade, senão por meio de um processo no qual se estabeleça diálogo entre os saberes, recompondo a relação entre homem e natureza (Leff, 2001). É também necessário repensar a ciência, o conhecimento e a tecnologia numa relação de cumplicidade entre os diferentes campos. É preciso inaugurar uma nova época. Hoje, a humanidade exige novos caminhos, novas respostas, sair dos guetos tradicionais do pensamento ocidental e aventurar-se em direção a novos saberes.

O mito moderno, no entanto, ainda é o mito da certeza racional - a razão torna-se, ainda, o único instrumento para conhecer a verdade. O mito da cientificidade, do progresso e do consumismo desenfreado, como resposta aos diferentes desafios da humanidade.

A atual crise da modernidade aponta para um pós, para um ainda $n \tilde{a} o$, que necessita constituir uma ordem simbólica, um campo aberto a vários campos de sentido. A modernidade teve como uma de suas consequências uma crise da ética, uma vez que na sociedade da técnica não há mais lugar para a tradição, para valores. Para sobreviver na modernidade será necessário edificar a ideia de um novo sujeito, com possibilidade de construir aventuras e experiências não apenas racionais em relação à vida e ao mundo em que vive, mas uma relação de cumplicidade, que descobre a subjetividade, que quer uma razão consistente para o bem-viver, uma relação que alguns teóricos chamam, hoje, de amorosa.

Uma concepção de vida e de mundo que enxergue o ser humano na sua inteireza, como razão e emoção, como ser pensante, mas criativo, sensível; mente e corpo entre outros corpos de uma mesma natureza que o abraça e que necessita do seu abraço, que o acolhe e o alimenta, mas que precisa ser acolhida e alimentada por ele. 
Assim, com base no exposto, emergem vários questionamentos sobre as relações do ser humano consigo mesmo, com a sociedade e com a natureza, com vistas a uma nova postura do homem diante da continuidade e da sustentabilidade da vida humana no planeta.

Como pensar a sociedade numa época em que a relação com a natureza apresenta uma crise profunda no tocante ao comportamento essencialmente exploratório que o homem tem a seu respeito? É possível promover adequações na relação do homem com o espaço natural que permitam visualizar sustentabilidade? A adoção de uma racionalidade ambiental é possível e é garantia de qualidade de vida para o homem e demais seres vivos? Em que dimensão a ética da vida pode impactar e melhorar a relação de equilíbrio da presença do homem na natureza? Estas e outras inquietações se impõem como campos necessários de reflexão, na busca de um paradigma para a relação ética entre o homem e a natureza. Isso será buscado a seguir, com o apoio do pensamento de Leff, não sem antes abordar a questão da relação do homem com a natureza, pois é preciso examinar os valores e os referenciais que orientam essa relação.

Segundo a proposta de Leff (2009), na construção das novas perspectivas para a sustentabilidade há um movimento social de questionamento das bases epistemológicas da racionalidade econômica hegemônica, apontando para uma racionalidade ambiental, conjugando novas categorias teóricas e novos direitos culturais, com novas estratégias produtivas, incluindo novas formas de autogestão, gerando seu próprio jeito de desenvolver e viver, fugindo dos modelos externos sempre apresentados como soluções que deram certo em outros territórios e outras culturas.

\section{REFERÊNCIAS}

BAUMAN, Zygmunt. Vida para consumo: a transformação das pessoas em mercadoria. Rio de Janeiro: Jorge Zahar Ed., 2008. 
BOFF, Leonardo. Ecologia: grito da terra, grito dos pobres. Rio de Janeiro: Sextante, 2004.

BRASIL. Agenda 21. Conferência das Nações Unidas Sobre Meio Ambiente e Desenvolvimento. Brasília: Senado Federal, 2001.

LEFF, Enrique. Ecologia, capital e cultura: a territorialização da racionalidade ambiental. Rio de Janeiro: Vozes, 2009.

Racionalidade ambiental: a reaproximação social da natureza. Rio de Janeiro: Civilização Brasileira, 2006.

. Saber ambiental. Sustentabilidade, racionalidade, complexidade, poder.

7. ed. Rio de Janeiro: Vozes, 2001.

PORTILHO, Fátima. Sustentabilidade ambiental, consumo e cidadania. São Paulo: Cortez, 2005.

RUSCHEINSKY, Aloísio (Org.). Educação ambiental: abordagens múltiplas. Porto Alegre: Artmed, 2002.

SEMPERE, Joaquim. Mejor con menos: necesidades, explosión consumista y crisis ecológica. Barcelona: Ed. Crítica, 2009.

TOURAINE, Alain. Crítica da modernidade. Petrópolis, RJ: Ed. Vozes, 2002.

Recebido em 21/9/2012

Aceito em 29/10/2012 